\title{
Formação em odontologia e interdisciplinaridade: o Pró-Saúde da UFSC
}

Daniela Lemos Carcereri*, Cláudio José Amante**, Marynes Terezinha Reibnitz***, Gianina Salton Mattevi****, Grasiela Garret da Silva*****, Ana Clara Loch Padilha******, Inês Beatriz da Silva Rath*******

* Membro do Comitê Gestor do Pró-Saúde, Tutora do PET-Saúde e da Residência Multiprofissional em Saúde da Família da Universidade Federal de Santa Catarina/UFSC. Subcoordenadora do Programa de Pós-Graduação em Odontologia da UFSC

** Pró-Reitor de Assuntos Estudantis da UFSC

*** Chefe do Departamento de Saúde Bucal da Secretaria Municipal de Saúde de Florianópolis-SC. Membro do Comitê Gestor do Pró-Saúde da UFSC

***** Doutoranda do Programa de Pós-Graduação em Odontologia Odontologia da UFSC - Área de concentração Odontologia em Saúde Coletiva

***** Mestranda do Programa de Pós-Graduação em Odontologia da UFSC Área de concentração Odontologia em Saúde Coletiva

****** Acadêmica do Curso de Graduação em Odontologia da UFSC, Membro do Comitê Gestor do Pró-Saúde, Representante Discente no Colegiado do Curso

******** Coordenadora do projeto Pró-Saúde do Curso de Graduação em Odontologia da UFSC

\section{RESUMO}

Na última década, a formação de profissionais de saúde tem sido reformulada com políticas de educação e de saúde promovidas pelos Ministérios da Educação e Cultura e da Saúde. Este artigo apresenta a experiência do Curso de Graduação em Odontologia da Universidade Federal de Santa Catarina (UFSC) na implantação do Programa Nacional de Reorientação da Formação Profissional em Saúde - Pró-Saúde. Como processo indutor, o programa direcionou as mudanças com vistas à integração ensino-serviço e à utilização de novas metodologias de ensino-aprendizagem, enfatizando a atenção básica. Na área de Odontologia, tais movimentos mostram-se necessários tendo em vista que, historicamente, tanto o sistema formador como o mercado de trabalho foram regidos pela iniciativa privada. Na UFSC, as atividades foram estruturadas em conformidade com os três eixos de desenvolvimento do Programa e impulsiona- ram o movimento de reforma curricular. O Pró-Saúde foi fundamental para a indução desse processo de mudança em uma perspectiva interdisciplinar, trazendo contribuições em todos os eixos.

\section{DESCRITORES}

Formação de Recursos Humanos. Educação em Odontologia. Recursos Humanos em Odontologia.

$\mathbf{N}$ a última década, a formação de profissionais de saúde tem sido reformulada com base em políticas de educação e de saúde promovidas em parceria por dois ministérios: o Ministério da Educação e Cultura (MEC) e o Ministério da Saúde (MS). Essas políticas sinalizam na direção de uma reforma curricular imprescindível nos cursos de graduação da área da saúde. ${ }^{3,8}$

Em 2002, ocorreu a homologação das Diretrizes Curriculares Nacionais para o Ensino de Graduação 
Formação em odontologia e interdisciplinaridade: o Pró-Saúde da UFSC • Carcereri DL, Amante CJ, Reibnitz MT, Mattevi GS, Silva GG, Padilha ACL, Rath IBS

em Odontologia (DCN), que preconizam formação generalista que atenda às reais necessidades da população brasileira, contemplando a atuação do cirurgião-dentista em equipes multiprofissionais e interdisciplinares. ${ }^{7}$

As DCN assinalam que, desde a graduação, o cirurgião-dentista deve ser preparado para atuar em equipes de saúde, conforme as necessidades da realidade do sistema de saúde vigente no país. ${ }^{14} \mathrm{~A}$ abordagem multidisciplinar objetiva habilitar equipes de estudantes para encorajarem famílias e comunidades a aceitarem assumir responsabilidades no controle de seus problemas de saúde e no seu autocuidado, como também, para ampararem os esforços dessas comunidades nesse sentido. Particularmente, a Odontologia, que sempre manteve um distanciamento das demais profissões de saúde, necessitará reaproximar-se e desenvolver oportunidades de aprendizado no que se refere a essa forma de trabalhar. ${ }^{10}$

Campos et al. ${ }^{9}$ (2009) relatam que o aprender não é passivo, mas sim ativo. Neste sentido, não há apenas uma realidade, porque cada um apreende uma situação de acordo com a aptidão que tem de percebê-la e a transforma a partir do conjunto de conhecimentos antecedentes, vivências e motivação que possui para aprender determinado tema. Para isso, há que elaborar, transformar e integrar o novo conhecimento aos seus saberes prévios, ampliando o enfoque do sistema educacional de maneira a contemplar não somente o ensino, mas também o aprendizado do aluno.

Aproximar a formação de médicos, cirurgiõesdentistas, enfermeiros e demais profissionais de saúde constitui um desafio no sentido de não somente direcioná-la à realidade do Sistema Único de Saúde (SUS), mas também de, através desse, aproximá-la das necessidades da população do país. Para isso é importante implementar transformações ideológicas, políticas e pedagógicas em todas as instituições formadoras de profissionais de saúde no Brasil. ${ }^{2} \mathrm{Na}$ área de Odontologia, tais movimentos mostram-se necessários, tendo em vista que, historicamente, tanto o sistema formador como o mercado de trabalho foram regidos pela iniciativa privada.

Nesse sentido, as políticas indutoras da formação em Odontologia, como o Programa Nacional de Reorientação da Formação Profissional em Saúde (Prósaúde $)^{6}$ e o Programa de Educação pelo Trabalho para a Saúde (PET-Saúde), ${ }^{5}$ propostas em parceria pelo MEC e MS, mostram-se oportunas e necessárias. O Quadro 1, a seguir, apresenta um breve histórico de eventos marcantes para o ensino de Odontologia no Brasil. ${ }^{19}$

Atualmente, observam-se sinais de mudança no panorama do trabalho odontológico, destacando-se a redução do exercício liberal estrito, a popularização dos sistemas de odontologia de grupo, o aumento do percentual de profissionais com vínculo público, sobretudo com o crescimento expressivo dos postos de trabalho na rede pública de serviços de odontologia. A inclusão do cirurgião-dentista no Programa Saúde da Família (PSF) e o surgimento dos Centros de Especialidades Odontológicas (CEO) na rede do SUS têm grande impacto nesses números. ${ }^{15}$

Tanto formadores como estudantes apresentam

Quadro1- Eventos históricos que marcaram o ensino da Odontologia.

\begin{tabular}{|c|c|}
\hline Ano & Evento \\
\hline 1884 & Início do ensino oficial da Odontologia no Brasil \\
\hline 1910 & $\begin{array}{l}\text { Publicação do relatório de Abraham Flexner (Estados } \\
\text { Unidos) - modelo biomédico (flexneriano) }\end{array}$ \\
\hline 1917 & $\begin{array}{l}\text { Bertrand Dawson (Inglaterra) - ações coletivas e } \\
\text { preventivas }\end{array}$ \\
\hline 1940 & $\begin{array}{l}\text { Criação e reforma de diversos cursos da Saúde } \\
\text { (América Latina) }\end{array}$ \\
\hline 1955 & $\begin{array}{l}\text { Reunião OPAS - redirecionar bases da formação e } \\
\text { da produção dos serviços de saúde }\end{array}$ \\
\hline 1956 & Criação da ABENO \\
\hline 1960 & $\begin{array}{l}\text { Críticas recorrentes ao modelo flexneriano } \\
\text { Início do movimento da Reforma Sanitária Brasileira }\end{array}$ \\
\hline 1970 & $\begin{array}{l}\text { Expansão e interiorização dos cursos de odontologia } \\
\text { Movimentos da Medicina Comunitária e Integração } \\
\text { Docente-Assistencial (Ensino-Serviço) }\end{array}$ \\
\hline 1978 & $\begin{array}{l}\text { Reunião de Alma-Ata - "Saúde para Todos" e "Estra- } \\
\text { tégia de Atenção Primária" }\end{array}$ \\
\hline 1980 & $\begin{array}{l}\text { Primeiras reformulações de currículo: atividades de } \\
\text { extensão }\end{array}$ \\
\hline 1986 & $\begin{array}{l}\text { VIII Conferência Nacional de Saúde } \\
\text { I Conferência Nacional de Saúde Bucal }\end{array}$ \\
\hline 1988 & $\begin{array}{l}\text { Constituição Federal - Saúde na Constituição } \\
\text { Regulamentação do Sistema Único de Saúde }\end{array}$ \\
\hline 1990 & Sancionada Lei Orgânica da Saúde \\
\hline 1993 & II Conferência Nacional de Saúde Bucal \\
\hline 2002 & $\begin{array}{l}\text { Aprovação das Diretrizes Curriculares Nacionais para } \\
\text { o Curso de Odontologia }\end{array}$ \\
\hline 2003 & $\begin{array}{l}\text { Criação da Secretaria de Gestão do Trabalho e da } \\
\text { Educação na Saúde }\end{array}$ \\
\hline 2004 & $\begin{array}{l}\text { III Conferência Nacional de Saúde Bucal } \\
\text { Criação do Fórum Nacional de Educação das Profis- } \\
\text { sões na Área da Saúde (FNEPAS) }\end{array}$ \\
\hline 2005 & Criação do Pró-Saúde (SGTES) \\
\hline 2008 & Criação do PET-Saúde e UNA-SUS (SGTES) \\
\hline
\end{tabular}

Fonte: Souza (2010, p. 49) 
conceitos em construção a respeito do papel do cirurgião-dentista na saúde coletiva. O que mostra que é imprescindível uma estreita relação entre o ensino superior e os serviços públicos de saúde, de maneira que se complementem alguns vazios na formação e na prática dos cirurgiões-dentistas na Equipe Saúde da Família (ESF). ${ }^{13}$

Devem ser articuladas redes de aprendizado que abranjam a academia e os serviços,para alcançar o objetivo de atender as demandas prementes e melhorar a assistência à saúde da população, mediante maior capacitação dos profissionais. ${ }^{9,2}$

O direcionamento de atividades pedagógicas para os ambientes ditos "extramuros" pode contribuir com as atividades multidisciplinares, que são pouco desenvolvidas no contexto da instituição de ensino. ${ }^{19}$

Percebe-se como um desafio à integração dos "mundos" da educação e do trabalho a superação da resistência e dos preconceitos que um nutre em relação ao outro. A integração tem como objetivo fundamental o compartilhamento de saberes entre esses dois polos durante a formação profissional, promovendo uma estreita relação entre teoria e prática de forma contextualizada. Para isso, deve haver reflexões e práticas, nas quais o conhecimento está associado a uma realidade específica de seu próprio espaço físico. ${ }^{2,1}$

A integralidade norteia a formação de um profissional mais justo, ético, humano, independentemente do mercado de trabalho em que ingressará, se público ou privado. ${ }^{12}$

O processo saúde-doença poderá ser abordado adequadamente somente quando tratado de maneira integral, pois é um fenômeno complexo e não limitado ao campo biológico. ${ }^{10}$ Para alcançar esse ideal é necessário ampliar a base conceitual da ação de cada profissional e, também, a conformação de equipes para a atuação multidisciplinar, buscando imprimir maior potência a cada ação. Dessa forma, segundo Souza, ${ }^{19}$ para alcançar esse objetivo é importante que os estudantes percebam, desde o início de sua formação profissional, a referência e contrareferência e estejam em contato com um processo de trabalho pautado nos princípios da integralidade.

O PRÓ-SAÚDE foi elaborado com base nas DCN para a área da saúde e no Sistema Nacional da Educação Superior, buscando sintonizar a formação em saúde às necessidades sociais, considerando as dimensões históricas, culturais e econômicas da população. ${ }^{6}$

Sua finalidade é formar profissionais com perfil adequado às necessidades sociais e isto implica fo- mentar a capacidade de aprender a aprender, trabalhar em equipe, comunicar-se, ter agilidade diante das situações, ter capacidade propositiva e habilidade crítica. $^{2}$

Alguns fatores parecem influenciar a presença da interdisciplinaridade: ${ }^{18}$

- Complexidade dos problemas;

- compatibilidade de paradigmas;

- atitude do sujeito de abertura ao novo, de engajamento ético e político, de valorização de outros saberes, reconhecimento da própria incompetência;

- diálogo, cooperação, articulação, afinidades pessoais, objeto e projeto comum;

- estrutura institucional favorável;

- desenvolvimento de competências para lidar com problemas novos, e com soluções por vezes parciais e provisórias;

- a existência de equipe multiprofissional;

- e processo de produção e reprodução do conhecimento com a participação dos diversos sujeitos que produzem saberes a respeito do objeto de estudo (p. 40)

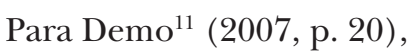

"as medidas principais da aprendizagem devem ser o saber pensar e o aprender a aprender, que farão da escola o centro da mudança que levará a sociedade à era do conhecimento".

O Curso de Graduação em Odontologia da UFSC reorientou, em 2005, o seu Projeto Pedagógico, ${ }^{20}$ no qual se ressalta que o curso tem como objetivos a contextualização, investigação e ensino dos saberes e fazeres da Odontologia, necessários para formar cirurgiões-dentistas habilitados para o exercício de uma profissão contemporânea, promotora de saúde e fundamentada nos preceitos da ética, da moral, da ciência, da filosofia e, principalmente, voltada para realidade da população brasileira. Em 2006, o Curso de Graduação em Odontologia da UFSC foi contemplado pelo PRÓ-SAÚDE, ${ }^{6}$ o que implicou o início do processo de reforma curricular do curso no primeiro semestre de 2007. Esse novo encaminhamento apontou a necessidade de utilização de novas metodologias educacionais e de reorganização da matriz curricular. $^{21}$

A Integração Ensino-Serviço vivenciada pelo Curso de Graduação em Odontologia da UFSC e pela Secretaria Municipal de Saúde de Florianópolis ${ }^{16}$ 
(SMS) está consoante com as DCN, atendendo os demais preceitos atuais de formação profissional em saúde. Com essa finalidade, têm sido desenvolvidas novas metodologias de ensino-aprendizagem, como a utilização de abordagens que orientam a participação ativa dos estudantes e propõem uma avaliação processual frente à proposta de ensino. ${ }^{19,20}$ Este artigo apresenta a experiência do Curso de Graduação em Odontologia da UFSC na implantação do Pró-Saúde, trazendo reflexões em torno do percurso vivenciado desde a sua implantação.

\section{Um pouco da nossa história: ações do Pró-Saúde Odontologia UFSC}

O Pró-Saúde, na UFSC, seguiu a estrutura do Programa, o qual se divide em três eixos de desenvolvimento.

O Eixo A - Orientação Teórica - compreende projetos de educação permanente, ${ }^{4}$ realização de oficinas de capacitação para auxiliares de saúde bucal (ASB) e técnicos de saúde bucal (TSB), capacitação para os profissionais de saúde da SMS. Estão contemplados neste eixo:

- análise e discussão do perfil epidemiológico do Município de Florianópolis, contribuindo com o Plano Municipal de Saúde;

- integração/expansão do Fórum de Experiências Exitosas Multiprofissionais da SMS; e

- produção de material didático-pedagógico.

Esse eixo contempla ainda a produção de conhecimento, com criação de infraestrutura para as atividades de investigação nas UBS, e o apoio a pesquisas sobre a atenção básica em parceria com o PET-Saúde.

O Eixo B - Cenário de Prática - prevê o projeto de rede de referência e contrarreferência em educação em saúde e atenção odontológica e a implantação do prontuário odontológico informatizado na UFSC. Até o momento, foram realizadas: a ampliação da área física das UBS, a diversificação dos cenários de prática e a construção de protocolos de atuação multiprofissional a agravos de maior prevalência, envolvendo estudantes, professores e profissionais da SMS.

O Eixo C - de Orientação Pedagógica - envolve ações como capacitação pedagógica para integração básico/clínica e em metodologias ativas para professores e profissionais que atuam nos diferentes cenários de prática. Para análise crítica do ensino na atenção básica, foi implementado um processo efetivo de participação e diálogo com as disciplinas envolvidas, bem como monitoramento e avaliação das atividades realizadas.

Os recursos financeiros aportados para o PróSaúde foram alocados para a instrumentalização da rede básica; apoio às oficinas; recursos para viabilização de seminários e elaboração de material didático; apoio para infraestrutura local; editoração e impressão gráfica de material didático e de resultados de investigação, como pôsteres, entre outros.

\section{Espaços de integração}

A implementação do projeto vem implicando a construção de espaços de integração entre as diversas dimensões envolvidas no processo:

- a integração ensino-serviço-comunidade;

- a integração do Curso de Graduação com a PósGraduação em Odontologia e do Curso de Graduação em Odontologia com outros Cursos de Graduação da área da Saúde;

- a integração das diferentes disciplinas em clínicas integradas de baixa, média e alta complexidade; e, por fim,

- a integração do discente à proposta.

A integração ensino-serviço-comunidade materializou-se principalmente na realização de Seminários de Integração Ensino-Serviço-Comunidade (SIESC) envolvendo a participação de docentes, profissionais técnico-administrativos, discentes e gestores da UFSC, da SMS e da Secretaria Estadual de Saúde (SES/SC), profissionais da rede (cirurgiões-dentistas, TSBs, ASBs), Coordenadores de Cursos de Odontologia de outras Instituições de Ensino Superior de Santa Catarina, representantes de Conselhos Comunitários e autoridades de órgãos de representação de classe. Esses Seminários foram fundamentais para a implantação da reforma curricular, dando visibilidade à nova filosofia de ensino-aprendizagem e permitindo construir uma compreensão sobre ela. Os Seminários foram realizados com a presença de professores convidados para abordar diferentes temáticas. O I SIESC, realizado em novembro de 2007 , contextualizou a política de formação na área da saúde no Brasil e no mundo, discutiu o conceito de saúde e o papel do SUS enquanto política pública de saúde. No II SIESC, realizado em agosto de 2008, foi debatida a temática da integralidade como eixo estruturante de diretrizes curriculares para cursos de graduação em odontologia, seus desafios para o ensino e para o serviço. Através de conferências e discussões em grupos formados por integrantes do ensino e do serviço promoveu-se o encontro de saberes e práticas. O III SIESC, reali- 
zado em junho de 2011, discutiu os desafios e perspectivas do Pró-Saúde e abordou também a temática específica da utilização de fluoretos em Odontologia.

No que se refere à integração do Curso de Graduação em Odontologia com a Pós-Graduação em Odontologia, observa-se que essa transcorre em diferentes cenários, contemplando o ensino, a pesquisa e a extensão. A seguir são ilustrados três exemplos:

- O projeto "Atenção Odontológica a pacientes internados no HU/UFSC" tem como objetivo a atuação da odontologia em ambiente hospitalar e vem trazendo benefícios à comunidade assistida, permitindo melhor entendimento da interrelação entre a saúde bucal e a saúde geral, além da valorização da inserção da odontologia no ambiente hospitalar;

- o Projeto "Escola Profa. Laura Lima", na linha programática de atenção à saúde integral da criança e do adolescente, tem como áreas temáticas a Educação e a Saúde. Este projeto de extensão capacita graduandos e pós-graduandos de Odontologia para a prática de educação comunitária em saúde, proporcionando-lhes aprendizado e trazendo benefícios para a comunidade;

- o projeto "NAPADF - Núcleo de Atendimento a Pacientes com Deformidade Facial", envolve diferentes especialidades da Odontologia e da Medicina. O Núcleo atende pacientes com deformidades faciais congênitas, na sua maioria crianças e adolescentes com fissura de lábio e/ou palato. $\mathrm{O}$ atendimento é realizado por estagiários de graduação e pós-graduação sob supervisão dos professores, desenvolvendo ações promotoras de saúde, educativas, preventivas e reabilitadoras.

No que se refere à integração do Curso de Graduação em Odontologia com outros Cursos de Graduação da área da Saúde é preciso ressaltar que, inicialmente, a relação serviço/ensino era mediada pelo Programa Docente Assistencial (PDA), através de convênio firmado entre UFSC e SMS desde 1989. Posteriormente, com aumento do número de cursos e de estudantes, houve necessidade de ampliar essa relação e criou-se a Rede Docente Assistencial (RDA), que reúne representantes de todos os Cursos de Graduação em Saúde, o Departamento de Saúde Pública, os Cursos de Residência da UFSC e o PET-Saúde. Visando a oferecer a oportunidade da vivência da multiprofissionalidade, os estágios de Odontologia foram então organizados de modo que os estudantes tivessem contato com os diferentes cursos de graduação, em especial com os cursos de enfermagem e medicina, também contemplados pelo edital Pró-Saúde I.

Posteriormente, os Cursos de Psicologia, Farmácia, Serviço Social, Nutrição e Educação Física foram contemplados pelo edital Pró-Saúde II, sendo possível ampliar essa integração. A participação da Odontologia no PET-Saúde I e II configura-se numa outra oportunidade de formação multiprofissional. A distribuição dos estágios na Rede de Saúde da $\mathrm{SMS}^{16}$ está apresentada na Figura 1, evidenciando a organização na lógica da multiprofissionalidade.

No que concerne à integração das diferentes disciplinas em clínicas integradas de baixa, média e alta complexidade, aponta-se que, após a realização da oficina sobre essa temática, sucedeu-se um período de diversas reuniões e intensas discussões, o qual findou na organização das clínicas por complexidade. Para sua estruturação buscou-se uma organização por núcleos, envolvendo diagnóstico, procedimentos clínicos e especialidades. Para cada núcleo foram definidas as áreas de competências, representadas por diferentes disciplinas e especialidades, de acordo com a complexidade e o desenvolvimento das habilidades dos graduandos.

Com relação à integração dos discentes à proposta; observa-se a participação ativa dos discentes do Curso de Odontologia nesse projeto, através de avaliações semestrais realizadas junto à coordenação do Curso, o que contribuiu para a concretização das adaptações necessárias e para o sucesso na implantação da nova proposta pedagógica. Os acadêmicos participam de todas as atividades propostas, tais como, seminários e oficinas e, através de seu site na internet, disponibilizam informações para a comunidade acadêmica. Ainda observa-se a adesão discente no colegiado do Curso e no Comitê Gestor do Pró-Saúde.

\section{Reflexões sobre o percurso vivido}

Desde 2005, temos vivenciado um processo intenso de ação-reflexão-ação sobre as atividades realizadas no âmbito do Pró-Saúde/UFSC. A Figura 2 explicita a complexidade desse processo, que transcorre em diferentes tempos e espaços, reúne profissionais da educação e da saúde, busca cada vez mais a participação da comunidade e compartilha distintos objetivos. Ao relacionar os conceitos bakhtinianos à realidade vivenciada durante o processo de implantação do PróSaúde na UFSC, apresentamos e refletimos sobre alguns de seus inúmeros cronotopos. 
Figura 1 - Mapa de distribuição dos locais de estágio por curso. Florianópolis, SC, 2010. Fonte: PMF-SMS (2010)

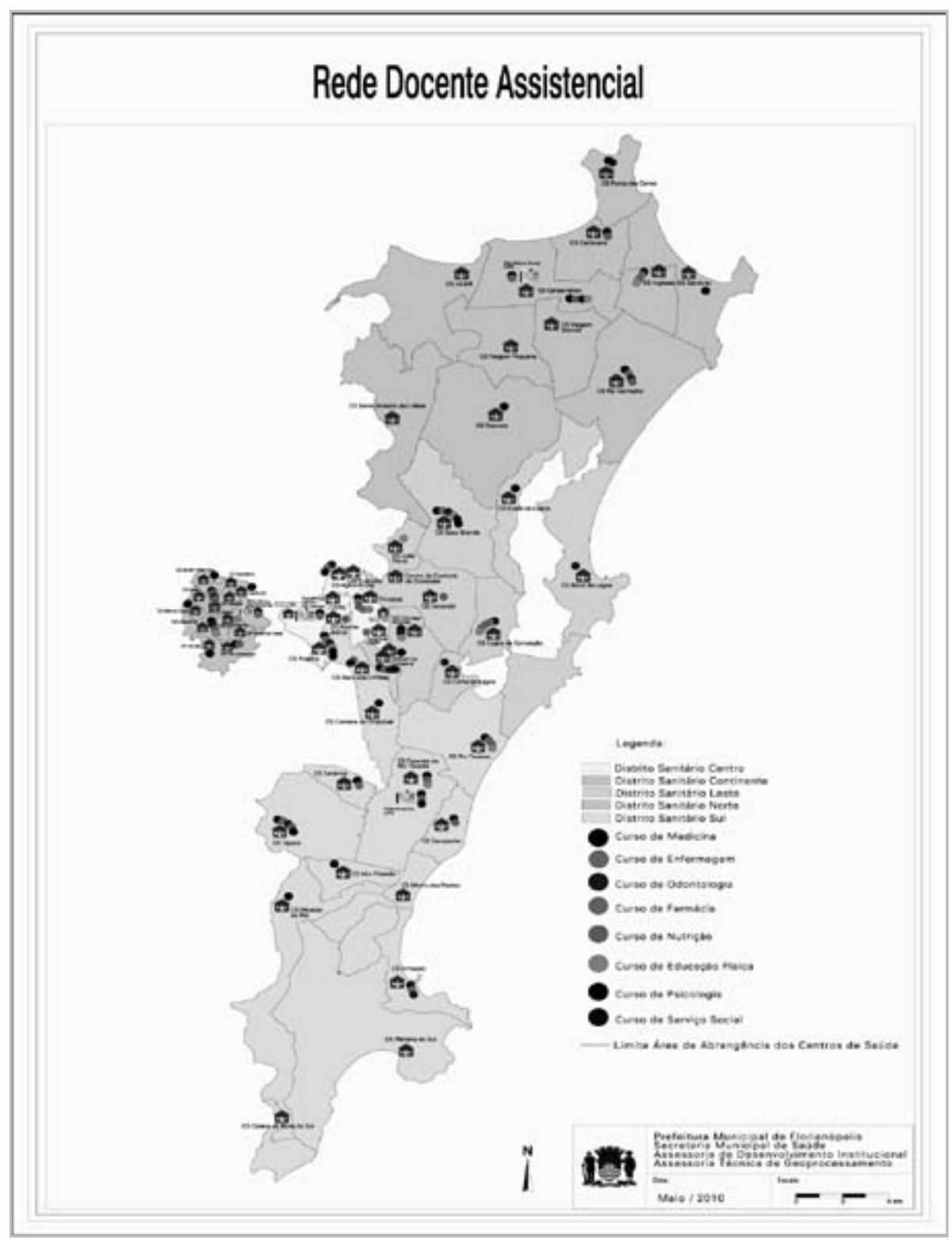

\section{Dimensão macrocronotópica do processo de reforma curricular - Pró- Saúde}

Segundo Rodrigues ${ }^{17}$ (2009), a expressão cronotopo foi cunhada pelo filósofo russo Mikhail Bakhtin, ao estudar os aspectos do tempo e do espaço a partir do romance grego. Sua origem está, portanto, ligada à teoria literária.

Ao analisar a dimensão cronotópica da escola, Rodrigues $^{17}$ (2009, p.186) destaca que:

\footnotetext{
A escola é um cronotopo extremamente complexo constituído por uma multiplicidade de cronotopos, que, de um lado, envolvem o aspecto temporal [...] Por outro lado, com relação ao aspecto espacial, a escola é um todo que,
}

se olhado de fora, não possibilita a visão dos pequenos cronotopos que existem dentro dela [...] Para se ver bem (analisar) um deles, é preciso se aproximar sem perder de vista que o espaço escolhido está inserido numa dimensão macrocronotópica.

A gestão do Pró-Saúde requer um olhar para esses diferentes tempos-espaços, ao mesmo tempo independentes e interligados entre si. Cada ponto destacado na figura envolve uma equipe de pessoas com determinado ritmo de trabalho, com saberes e crenças provenientes de sua constituição pessoal e profissional.É preciso saber elencar prioridades, gerir o tempo de forma a garantir que todos os pontos sigam avançando em suas ações, sem perder de vista a necessária 


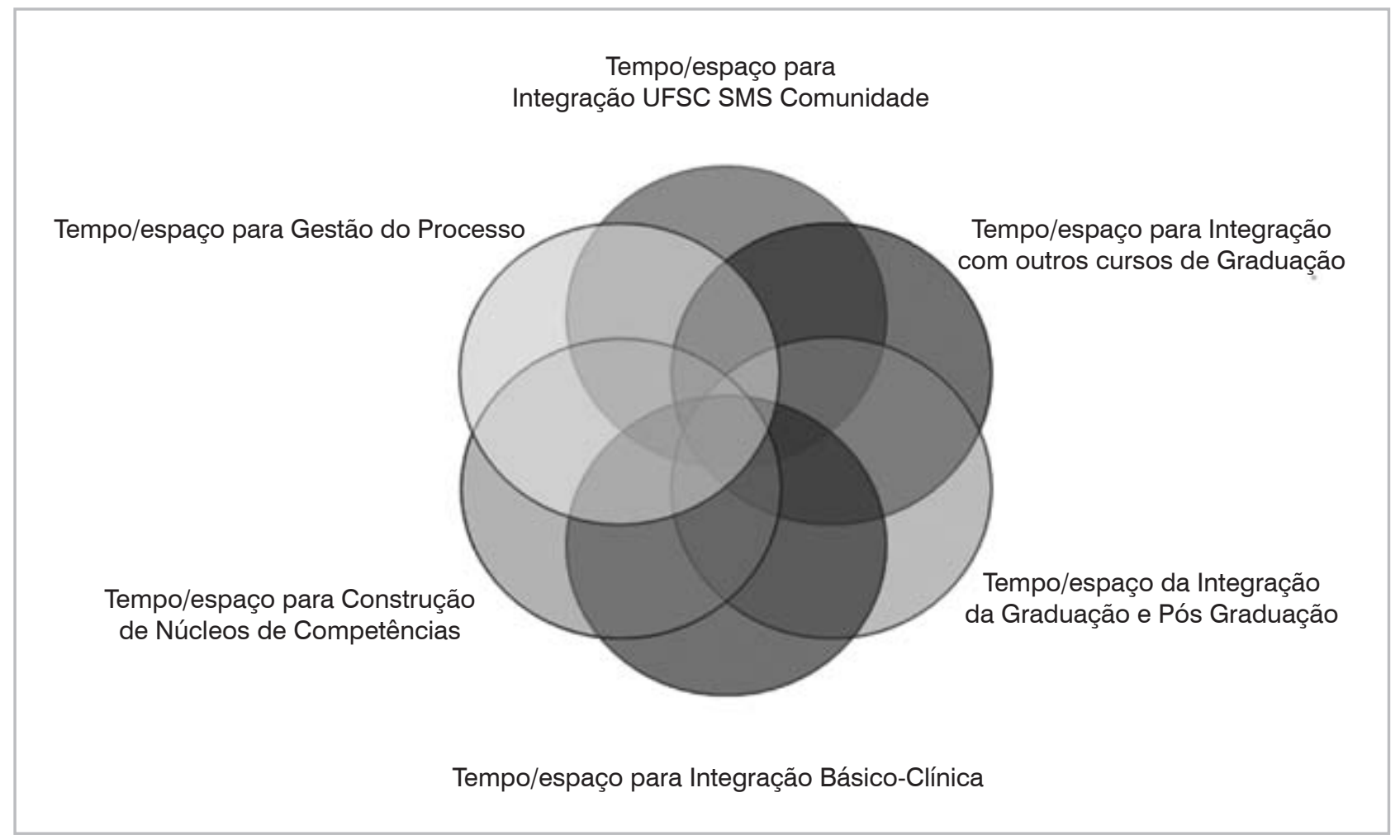

Figura 2 - Dimensão macrocronotópica do processo de reforma curricular - Pró-saúde Odontologia UFSC. Fonte: Adaptado de Rodrigues (2009)

interação para atingir os objetivos que são comuns. É sem dúvida um processo que encerra elevado grau de complexidade, pois diferentes demandas e diferentes pontos de vista se encontram e se confrontam nesses tempos-espaços de discussão/ação.

Algumas dificuldades foram transpostas como, por exemplo, agregar novos atores ao grupo gestor; outras, no entanto, ainda estão a requerer empenho constante, como a de lidar com a gestão financeira do Programa. É, portanto, tarefa para muitos e por muito tempo.

A realização dos SIESCs foi estratégica e configurou a oportunidade de problematizar junto aos envolvidos o cenário atual da formação em saúde no Brasil e no mundo, deslocando assim a discussão do fórum local. Tais Seminários contribuíram para diminuir as resistências à proposta de mudança curricular e, mais que isso, promoveram a integração, angariando adeptos tanto no ensino como no serviço.

A integração ensino-serviço-comunidade tem na RDA uma grande fortaleza. Trata-se de um espaço de articulação interinstitucional UFSC/SMS, no qual é discutida e encaminhada a operacionalização dos diferentes projetos propostos em parceria, voltados para potencializar a formação em saúde para o SUS.
É um espaço legalmente constituído e que conta com a legitimidade necessária para desenvolver suas atividades. Através da RDA são promovidos os Seminários Pró-Saúde, nos quais cada curso pode relatar o andamento de seus projetos, bem como conhecer e compartilhar a realidade de outros cursos.

O envolvimento da UFSC e, em especial, da Odontologia, nos projetos Pró-Saúde, PET-Saúde, Residência Multiprofissional em Saúde da Família, Residência Multiprofissional em Saúde em âmbito hospitalar, UNASUS, e TELESSAÚDE facilita a nossa integração com os demais cursos de graduação da área da saúde. Todos esses projetos são de natureza multiprofissional e promovem reuniões e eventos que sinergicamente potencializam a construção da interdisciplinaridade. Este é, sem dúvida, um diferencial da UFSC na operacionalização do Pró-Saúde, evidenciando a vocação para o trabalho interdisciplinar.

A integração graduação e pós-graduação ocorre através do Estágio Docência e de outros estágios do currículo da graduação; atividades de pesquisa e extensão como ação estratégica para preparar docentes para atuar nessa nova lógica. A atuação dos bolsistas do Programa de Apoio ao Plano de Reestruturação e Expansão das Universidades Federais (REUNI) junto 
aos graduandos também proporciona um momento rico para o futuro professor do Curso de Graduação em Odontologia, que tem a oportunidade de vivenciar o dia a dia da profissão, contribuindo para o enfrentamento das dificuldades apresentadas.

Um grande desafio está em potencializar o eixo $\mathrm{C}$ - orientação pedagógica. Desconstruir o paradigma cartesiano que fragmentou saberes em diferentes disciplinas é uma tarefa árdua e que requer tempo e persistência. Ainda que algumas estratégias tenham sido implementadas com sucesso, como é o caso da formação das clínicas por complexidade, novas estratégias precisam ser formuladas.

\section{CONSIDERAÇÕES FINAIS}

Embora tenham ocorrido movimentos significativos de reflexão crítica sobre os modelos tradicionais de formação profissional nas áreas de Medicina e Enfermagem, em relação à Odontologia, existe um atraso histórico, que vem sendo revisto através de um movimento de reaproximação das diferentes especialidades odontológicas e da odontologia com os demais cursos da área da saúde. É necessário daqui para frente reunir esforços para que possamos integrar a saúde bucal dentro do novo contexto de ação interdisciplinar e multiprofissional, formando um profissional com perfil adequado às necessidades do mundo contemporâneo. Este movimento vem sendo muito desafiador, tendo em vista a dificuldade em integrar professores com perfil especialista numa lógica de ensino generalista e interdisciplinar.

O percurso vivido aponta que o Pró-Saúde se mostrou fundamental para indução desse processo de mudanças, suscitando avanços no "serviço" e no "ensino". Além dos recursos financeiros atrelados ao PróSaúde, para a realidade da UFSC, o Programa foi importante na medida em que evidenciou que tais mudanças compunham uma política pública. Nesse sentido, foi um respaldo essencial para a defesa dos princípios norteadores e, em alguma medida, contribuiu para que o discurso da mudança não fosse personificado na figura dos gestores do Programa, do Curso e/ou dos Departamentos de Ensino. Da mesma forma, o PET-Saúde trouxe a possibilidade da articulação da academia com o serviço, além de propiciar a aproximação dos demais cursos da área da saúde. Nesse sentido, os programas de Residência têm propiciado aos egressos dos cursos uma nova perspectiva de trabalho, tanto em relação à diversificação dos cenários de prática,,como no convívio profissionalacademia-serviço-comunidade.
Ainda há que se trabalhar para vencer resistências, transformar o pensamento através da reflexão, da avaliação dos resultados obtidos e da implementação das reformulações necessárias para se obter um egresso cirurgião-dentista com as características e qualidades desejadas para o desempenho de suas funções, dentro dos princípios norteadores do SUS.

Os projetos envolvidos no Pró-Saúde e nos demais programas têm sido apresentados em diferentes eventos científicos tais como: Reuniões da Associação Brasileira de Ensino Odontológico - ABENO, Congresso Internacional de Odontologia de São Paulo - CIOSP, Rede Unida, ABRASCO, Sociedade Brasileira de Pesquisa Odontológica - SBPqO, a Expo-SGTES - Trabalho e Educação na Saúde, do MS e na Semana de Ensino Pesquisa e Extensão da UFSC - SEPEX, entre outros, dando visibilidade ao Programa e ao processo de reforma curricular da UFSC.

O Pró-Saúde no Curso de Odontologia da UFSC alavancou processos interdisciplinares já presentes na instituição desde a década de 70, os quais ocorriam de maneira isolada, a partir de iniciativas particulares de alguns docentes, sendo fundamental para a indução do processo de mudança na formação em odontologia na UFSC, na perspectiva multiprofissional e interdisciplinar, e trazendo contribuições nos três eixos de desenvolvimento do Programa.

\section{ABSTRACT}

\section{Interdisciplinarity and dentistry training: UFSC's Pro-Health program}

In the last decade, the training of health professionals was restructured with education and health policies promoted in partnership by the Ministries of Education and Culture and Health. This article presents the experience of the Undergraduate Dentistry Course of the Federal University of Santa Catarina (UFSC) gained in implementing the National Redirection of Vocational Training in Health - Pro-Health. As an inductive process, it led to changes, aiming at integrating learning and health service and at using new methods of teaching and learning, emphasizing primary care. In the field of dentistry, these movements seemed necessary, considering that, historically, both the educational system and the labor market were governed by private initiative. In UFSC, the activities were structured in accordance with the three axes of development presented by the program, and drove the movement to reform the curriculum. Pro-Health was essential for inducing the process of change in an interdisciplinary perspective, offering contributions across all axes. 


\section{DESCRIPTORS}

Human Resources Formation. Dental Education. Dental Staff. -

\section{REFERÊNCIAS BIBLIOGRÁFICAS}

1. Albuquerque VS, Gomes AP, Rezende CHA, Sampaio MX, Dias OV, Lugarinho RM. A Integração Ensino-serviço no Contexto dos Processos de Mudança na Formação Superior dos Profissionais de Saúde. Rev Bras Educ Med 2008; 32(3) [acesso em 2010 set 25]; 356-362. Disponível em: http://www.fepecs.edu. br/cies2010/artigo03.PDF .

2. Araujo, ME, Zilbovicius C. A formação acadêmica para o trabalho no Sistema Único de Saúde (SUS) In: Moysés ST, Kriger L, Moysés SJ, orgs. Saúde Bucal das Famílias: Trabalhando com Evidências. São Paulo: Artes Médicas; 2008. p. 277-290.

3. Brasil. Ministério da Saúde. Secretaria de Gestão do Trabalho e da Educação na Saúde. A Educação e o Trabalho na Saúde: A Política e suas Ações. Brasília: Ministério da Saúde; 2009.

4. Brasil. Ministério da Saúde. Secretaria de Gestão do Trabalho e da Educação na Saúde. Departamento de Gestão da Educação em Saúde. Política Nacional de Educação Permanente em Saúde. Brasília: Ministério da Saúde; 2009.

5. Brasil. Ministério da Saúde. Portaria Interministerial $n^{\circ} 421$ de 3 de março de 2010. Institui o PET-Saúde para a formação de grupos de aprendizagem tutorial em áreas estratégicas do SUS. [acesso em 2010 set 17] Disponível em: http://portal.saude. gov.br/portal/saude/profissional/visualizar_texto. cfm?idtxt $=33018$

6. Brasil. Ministério da Saúde. Ministério da Educação. Programa Nacional de Reorientação da Formação Profissional em Saúde - Pró-Saúde: objetivos, implementação e desenvolvimento potencial. Brasília: Ministério da Saúde; 2007.

7. Brasil. Ministério da Educação. Conselho Nacional de Educação. Câmara de Educação Superior. Resolução CNE/CES no 3 de 19 de fevereiro de 2002. Institui diretrizes curriculares nacionais do curso de graduação em Farmácia e Odontologia. Diário Oficial da União. Brasília, 4 mar. 2002; Seção 1, p.10 .

8. Brasil. Ministério da Saúde. Secretaria de Gestão do Trabalho e da Educação na Saúde. SGTES. [acesso em 2010 set 13] Disponível em: http:/ / portal.saude.gov.br/portal/sgtes.

9. Campos FE, Brenelli SL, Lobo LC, Haddad AE. O SUS como Escola: a responsabilidade social com a atenção à saúde da população e com a aprendizagem dos futuros profissionais de saúde. Rev Bras Educ Med 2009;33(4) [acesso em 2010 set 13]; 513-514. Disponível em: http://www.scielo.br/pdf/rbem/ v33n4/v33n4a01.pdf.

10. Ceccim RB, Feuerwerker LCM. Mudança na graduação das profissões de saúde sob o eixo da integralidade. Cad Saúde
Pública. 2004;20(5):1400-1410.

11. Demo P. Conhecimento e aprendizagem - a atualidade de Paulo Freire. Revista da ABENO 7(1): 20-37, jan./abr. 2007.

12. Ferreira EF, Vargas AMD, Amaral JHL, Vasconcelos M, Mattos FF. Travessia a caminho da integralidade: uma experiência do curso de odontologia da UFMG. In: Pinheiro R, Ceccim RB, Mattos RA, orgs. Ensino-trabalho-cidadania: novas marcas ao ensinar integralidade no SUS. Rio de Janeiro: UERJ, IMS: ABRASCO; 2006. p. 85-91.

13. Matos PES, Tomita NE. A Inserção da Saúde Bucal no Programa de Saúde da Família: da universidade aos pólos de capacitação. Cad Saúde Pública. 2004;20(6):1538-1544.

14. Morita MC, Haddad AE. Interfaces da área da Educação e da Saúde na perspectiva da formação e do trabalho das equipes de Saúde da Família. In: Moysés ST, Kriger L, Moysés SJ, orgs. Saúde Bucal das Famílias: Trabalhando com Evidências. São Paulo: Artes Médicas; 2008. p. 268-276.

15. Morita MC, Haddad AE, Araújo ME. Perfil atual e tendências do cirurgião-dentista brasileiro. Maringá: Dental Press; 2010.

16. PMF. Prefeitura Municipal de Florianópolis. Secretaria de Saúde. Histórico da Rede Docente-Assistencial [acesso em 2010 set 15] Disponível em: http://www.pmf.sc.gov.br/saude/.

17. Rodrigues NC. O discurso do professor de língua portuguesa no processo de reestruturação curricular: uma construção dialógica. [Tese de Doutorado]. Florianópolis: Universidade Federal de Santa Catarina; 2009. [acesso em 2010 set 17]. Disponível em: http://www.tede.ufsc.br/teses/PLLG0439-T.pdf

18. Scherer MDA, Pires D. A interdisciplinaridade prescrita para o trabalho da equipe de saúde da família, na percepção dos profissionais de saúde. Tempus - Actas de Saúde Coletiva . 2009;3(2): 30-42.

19. Souza, AL. Integração Ensino-Serviço no Curso de Graduação em Odontologia da Universidade Federal de Santa Catarina. [Dissertação de Mestrado]. Florianópolis; Universidade Federal de Santa Catarina; 2010. [acesso em 2010 set 20]. Disponível em: http://www.tede.ufsc.br/teses/PODO0362-D.pdf

20. Souza, A. L.; Carcereri, D. L.. Estudo qualitativo da integração ensino-serviço em um curso de graduação em Odontologia. Interface (Botucatu. Impresso) 2011:15(39) set./dez [prelo] .

21. UFSC. Universidade Federal de Santa Catarina. Centro de Ciências da Saúde. Coordenadoria do Curso de Odontologia. Projeto político-pedagógico do Curso de Graduação em Odontologia, 2006. [acesso em 2010 set 15] Disponível em: http:// www.odontologia.ufsc.br. 